\title{
Elastic Behavior and Creep of Refractory Bricks Under Tensile and Compressive Loads
}

\author{
By Lewis E. Mong
}

\begin{abstract}
Nine brands of firebrick, including two high alumina, four fire clay, two siliceous, and one silica, were subjected to creep tests. Specimens were cut from 9-inch bricks. Creep tests, with either tensile or compressive stresses, were made at 11 temperatures from $25^{\circ}$ to $950^{\circ} \mathrm{C}$, inclusive. Durations of tests were approximately 240 days. Small length changes, independent of stress direction, ${ }^{1}$ occurred at the lower temperatures. Lowest temperatures at which creep was significant were high alumina, $700^{\circ}$ to $850^{\circ} \mathrm{C}$; fire clay, $600^{\circ}$ to $700^{\circ} \mathrm{C}$; siliceous and silica, $950^{\circ} \mathrm{C}$. Creep results with compressive stresses could not be correlated with results with tensile stresses. At $950^{\circ} \mathrm{C}$, specimens of different brands showed greatly different capacities to carry load. Repeated heatings caused growth of silica brick. Moduli of elasticity at room temperature were determined before and after the various heat treatments, and resultant changes in moduli are recorded. The changes were large for silica brick and small for the fire-clay brick.
\end{abstract}

\section{Introduction}

The lowest temperature at which firebrick exhibit appreciable permanent deformation or creep $^{2}$ as a result of working stresses maintained for long periods of time is of interest in many modern uses of refractory materials where a definite shape must be maintained under load and at elevated temperatures. In interpreting thermal spalling performance $[1],{ }^{3}$ it is necessary to determine the range of temperature over which the material remains rigid and is subject to cracking. It is important also to have a knowledge of flow characteristics at the lower temperatures to

\footnotetext{
1 "Stress direction" is used in this paper to indicate either tensile or compressive loading.

2 The definition of "creep," from Webster's New International Dictionary (1939), is "to undergo permanent deformation from prolonged exposure to high temperatures or stress." However, "creep" is used in this report to indicate only deformations caused by combined temperature and stress.

${ }^{3}$ Figures in brackets indicate the literature references at end of this paper.
}

determine the amount of stress relief such flow might allow [2]. It was the purpose of this investigation to provide some information on these properties as well as to provide some data indicating the stresses that may safely be used in tension [3].

\section{Materials}

Firebrick representing nine brands were submitted by eight manufacturers. The laboratory identification numbers are identical with those assigned the same brands in an earlier report [4]. Brick of these brands were selected because their compositions represent a wide range in the silicaalumina ratio. For convenience, the type of brick, the method of manufacture, pyrometric cone equivalent, porosity, and the maturing temperature [5] are given in table 1, together with the chemical analysis. 
TABLE 1.-Properties of firebrick

\begin{tabular}{|c|c|c|c|c|c|c|c|c|c|c|c|}
\hline \multirow{2}{*}{ Brand } & \multirow{2}{*}{ Type of brick } & \multirow[b]{2}{*}{ ' } & \multirow{2}{*}{$\begin{array}{l}\text { Method } \\
\text { of manu- } \\
\text { facture } 1\end{array}$} & \multirow{2}{*}{$\begin{array}{l}\text { Pyro- } \\
\text { metric } \\
\text { cone } \\
\text { equiva- } \\
\text { lent }\end{array}$} & \multirow{2}{*}{ Porosity } & \multirow{2}{*}{$\begin{array}{l}\text { Matured } \\
\text { at cone- }\end{array}$} & \multicolumn{5}{|c|}{ Chemical composition } \\
\hline & & & & & & & $\mathrm{SiO}_{2}$ & $\mathrm{Al}_{2} \mathrm{O}_{3}$ & $\begin{array}{l}\text { Total } \\
\text { flux }\end{array}$ & $\mathrm{Fe}_{2} \mathrm{O}_{3}+\mathrm{TiO}_{2}$ & $\mathrm{P}_{2} \mathrm{O}_{5}$ \\
\hline 19 & High alumina. & 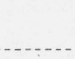 & DP & $\ldots$ & $\begin{array}{r}\text { Percent } \\
26.8\end{array}$ & & $\begin{array}{r}\text { Percent } \\
14.9\end{array}$ & $\begin{array}{r}\text { Percent } \\
79.3\end{array}$ & $\begin{array}{r}\text { Percent } \\
5.7\end{array}$ & $\begin{array}{r}\text { Percent } \\
4.1\end{array}$ & $\begin{array}{r}\text { Percent } \\
0.39\end{array}$ \\
\hline 18 & . . . do do . . . . & & DP & 35 & 19.8 & -.. & 36.8 & 55.7 & 7.4 & 3.8 & .36 \\
\hline 1 & Fire clay ... & (n.... & DP & 34 & 16. 2 & & 47.8 & 44.4 & 7.8 & 3.1 & 106 \\
\hline 6 & ..... do ....... & - & S.M & $32-33$ & 21.5 & 9 & 52.0 & 41. 2 & 6.8 & 4.4 & 0.18 \\
\hline 11 & _... do ..... & & DP & $32-33$ & 18. 7 & 14 & 56.9 & 37.8 & 5.3 & 2.5 & .52 \\
\hline 7 & $\ldots$..... do & (n) & $\mathrm{HM}$ & 32 & 25.1 & 9 & 58.5 & 34.8 & 6.7 & 4.1 & .09 \\
\hline 15 & Siliceous & (n) & SM & $31-32$ & 25.4 & 13 & 65.3 & 29.4 & 5. 3 & 3.5 & .08 \\
\hline 16 & _.... do . . . & (n..... & $\mathrm{HM}$ & $29-30$ & 29.9 & $-\cdots$ & 80.7 & 16.1 & 3. 2 & 2.4 & .07 \\
\hline 17 & Silica & (n) & $\mathrm{HM}$ & $32-33$ & 29.3 & 16 & 96.0 & & & & \\
\hline
\end{tabular}

1 DP, SM, and HM refer to dry press, stiff-mud, and handmade, respectively.

\section{Specimens and Apparatus}

\section{Preparation of Specimens}

Specimens were cut from standard 9-inch straight brick as received from the manufacturers. Two specimens were obtained from a single brick and the dimensions are shown at $A$ in figure 1. This type of specimen has been described [4], and it was used in this work in all the tests in which the material was stressed for extended periods. Specimens having such defects as visible laminations, unusually large voids, or having exceptionally low moduli of elasticity were discarded.

Only five specimens were used in tests without stress. They were 1-inch square and 9 inches long, and were taken from one brick of brand 17 .

Two pairs of gage marks were placed on each specimen, as shown at $B$ in figure 1 . One pair faced the original edge of the brick and the other pair, diametrically opposite faced the original middle of the brick.

The gage marks consisted of silicon-carbide particles, grit No. 180, cemented to the specimen with Alundum cement. The silicon carbide and cement were mixed with water to a thin creamy consistency, and a small drop of the material was placed on the specimen. After the drop was partially dry, it was washed with single drops of water to expose the outlines of several siliconcarbide particles.

The specimens that were stressed in the tests were subjected to a preliminary heating and cooling to mature the cement around the gage marks, to relieve residual stresses in the machined specimens, and to provide a similar cooling treatment for all specimens. This heating and cooling (which will be referred to in this paper as preheating) consisted in raising the temperature of the specimens to $900^{\circ} \mathrm{C}$ in an electric furnace in 5 hours, maintaining this temperature for one-half hour, and then permitting the specimens to cool with the furnace.

\section{Apparatus for Modulus of Elasticity Tests}

The modulus of elasticity in tension of the specimens at room temperature was determined with the apparatus previously described [4], using a 6 -inch gage length. The gage mountings were placed on the specimens so that the Tuckerman gages indicated strains for the same gage lengths shown at $B$ in figure 1 .

\section{Apparatus for Creep Tests}

\section{(a) Description}

Figure 1 shows a sectional view of the apparatus and the assembly of parts used for the testing of one specimen in compression, and also the assembly of parts for loading a specimen in tension. The entire apparatus and furnace for compressive loading accommodated 10 specimens in a single furnace, and a similar furnace for tensile loading accommodated 7 specimens. However, the space for one test specimen in the compressive apparatus was occupied by a reference bar of fused quartz with gage marks similar to those on the test specimens. An invar bar, marked and measured to an accuracy of \pm 0.00002 in., was used as the reference length at room temperature. The telescope eyepieces were equipped with green filters (Wratten No. 57 A) to avoid loss of contrast resulting 




VERTCAN SECTIOW ACROSS APPARATUS, FOR COMPRESSIVE LOADS

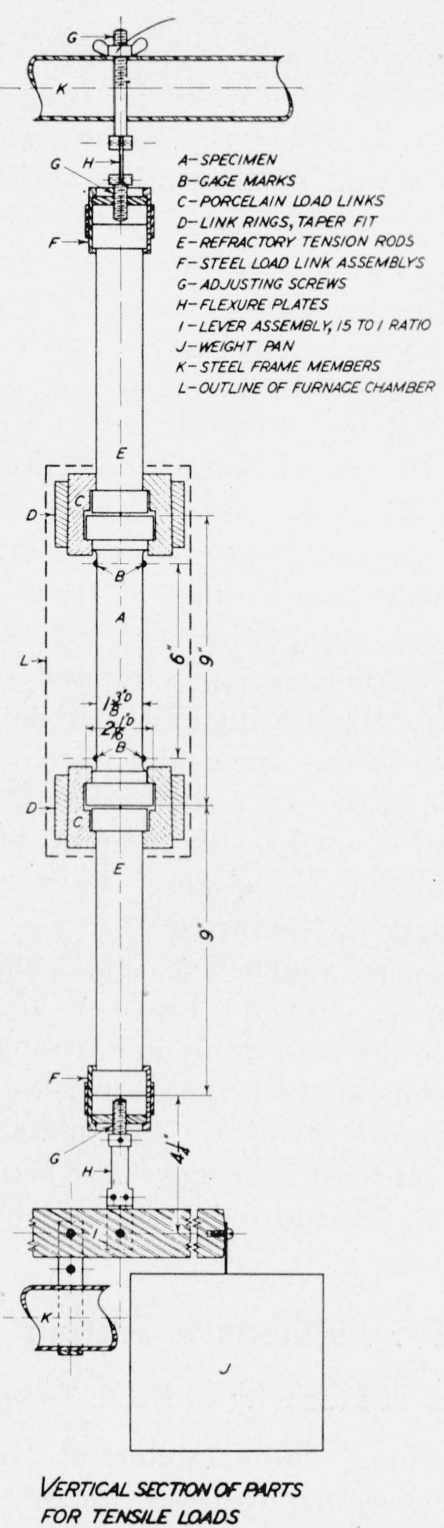

VERTICAL SECTTONOF ANTS

Figure 1.-Apparatus used for compressive and tensile creep tests.

from light radiated by the specimens at test temperatures of $850^{\circ} \mathrm{C}$ and above.

The porcelain, refractory, and steel parts transmitting loads to the specimens were finished to obtain a common axis for each assembly. The combination of links and rod to transmit tensile loads to the specimen was found to be the best of three different styles because it proved to be the most economical in time and materials to manufacture, and the alinement obtained was most satisfactory.

Temperatures within the furnace were indicated by six base-metal thermocouples placed at the ends and at the middle of the furnace at heights shown in figure 1. One thermocouple in each furnace operated a galvanometer that controlled the action of a double-throw relay. This in turn connected high or low voltages from a tapped transformer to the furnace to maintain a constant temperature.

(b) Precision of Measurement

The error for the determination of the tensile modulus of elasticity at room temperature was

\section{Creep of Refractory Brick}


\pm 2 percent, as previously reported [4]. The scale of the micrometer slide could be read to 0.0002 $\mathrm{cm}$. However, errors of the entire gage system, such as those caused by the window of the furnace, lack of sharp outline of gage marks, loss of contrast at the higher temperatures, temperature changes of the telescopes and slide during use, and play within the micrometer slide, made it impossible to repeat length measurements within tolerances less than $\pm 0.001 \mathrm{~cm}$, which was equivalent to $\pm 6 \times 10^{-5} \mathrm{in}$./in., or to a percentage change of \pm 0.006 . When the windows were not tightly sealed much greater errors were evident.

The controlled temperature of the furnaces [6] varied less than $\pm 3 \mathrm{deg} \mathbf{C}$, but the temperatures indicated by the six thermocouples differed by as much as $9 \mathrm{deg} \mathrm{C}$ after the heating units had deteriorated. Temperatures at the upper and lower gage-mark levels were equalized by a rheostat shunted across the upper half of the heating element, but no control was available to equalize the temperatures along the length of the furnace.

Pan loads are weighed to the nearest onesixteenth ounce. Lever ratios were obtained by calibrating the lever assembly in a testing machine. Frictional errors of the lever assemblies amounted to less than 0.1 percent. Considerably larger errors in the applied load may have resulted from the vibration transmitted from the building to the apparatus.

\section{Methods of Testing}

\section{Modulus of Elasticity at Room Temperature}

In determining the modulus of elasticity in tension, the specimen load was limited so that the maximum strain did not exceed 0.007 percent. The modulus of elasticity was obtained for each specimen after it had been preheated and again after it had been subjected to a creep test. It was determined also for some specimens before the preheating and for others after various periods of storage at room temperature.

Modulus of elasticity in compression was determined for only two specimens of each of eight brands, and values were obtained only after the preheating.

\section{Creep Tests}

Gage lengths were determined after the specimens were assembled in the furnace and before the specimens were loaded or heating started. Telescope cross hairs were alined on single particles of silicon carbide having sharp outlines and a sketch drawn of each gage mark showing the position of the selected particle. This particle was used in subsequent measurements. The exact specimen gage length was calculated from the known reference-bar length and the two readings, on the scale of the micrometer slide, obtained when the telescopes were alined on the reference bar or on the specimen gage marks. A similar procedure was followed for the gage marks diametrically opposite.

Following the exact determination of the gage lengths, the temperature was raised to the test temperature at approximately $40 \operatorname{deg} \mathrm{C}$ per hr, and, after holding this temperature at least 3 hours, the gage lengths were determined again. The specimen was then loaded and gage lengths observed immediately and at approximately $30-$ day intervals for the duration of the test. Lastly, gage lengths were obtained after the removal of the load at the test temperature and also after cooling the specimen to room temperature. Some additional length values were taken while the stressed specimen was at the elevated temperature if there were indications that the specimen might break in the interim between observations.

Creep tests were made at the following temperatures $\left({ }^{\circ} \mathrm{C}\right): 25,125,250,350,450,600,700$, $800,850,900$, and 950 .

For those tested in tension the stress applied to each specimen was $7 \times 10^{-5}$ times the modulus of elasticity in tension determined on that particular specimen at room temperature, and for those tested in compression, the stress was double the stress used in the tension test. This scheme was followed because it had been found [4] that, at room temperature, strength is approximately proportional to modulus of elasticity and, therefore, the load on each specimen was nearly proportional to its strength.

The stress factor ${ }^{4}$ of $7 \times 10^{-5}$ was selected because preliminary tests indicated this value to be the greatest that could be used in tension for brick of all brands without rupture when loaded at room temperature. Specimens in compression

\footnotetext{
${ }^{4}$ In this paper, "stress factor" is the ratio of the stress for a specimen in a creep test to the tensile modulus of elasticity at room temperature for that specimen.
} 
ordinarily fail at stresses far greater than $7 \times 10^{-5}$ times the modulus of elasticity, and, therefore, the factor was doubled to accentuate the creep. Other tensile stresses were used in supplementary tests at $950^{\circ} \mathrm{C}$.

Specimens were used in more than one creep test if their moduli of elasticity had not changed more than 7.5 percent when compared to the value obtained following the preheating or if their overall length change did not exceed $15 \times 10^{-5}$ in./in. If the change was greater than either of these limits, the specimen was considered no longer representative of the brand and a new specimen was used in the next test.

Each brand was represented in the creep test at a given temperature by only one specimen. Creep tests were repeated only at $450^{\circ} \mathrm{C}$ in tension, using a different lot of specimens.

\section{Specimens Without Load}

Lengths of 1-inch-square specimens of brand 17 subjected to heating without loading were obtained at room temperature only. The measurements were made on untreated specimens and again after each heating. The length changes resulting from each heating were calculated in percent and the cumulative changes recorded.

\section{Results and Discussion}

\section{Modulus of Elasticity}

(a) Variations Along Width of Brick

In the determination of the modulus of elasticity, the strains indicated by the gage facing the original middle of the brick, and the gage facing the original edge of the brick, were usually different. These total differences, more than 100 percent when based on the average strain for some specimens, indicated variation across the section of the specimen in a direction parallel to the width of the original brick. Larger center strains, indicating "soft cores," were found for brick of brands 6,7 , and 15 . These bricks were manufactured either by the handmade repressed or the stiff-mud repressed method. The high-silica handmade bricks (brands 16 and 17) had larger edge strain, possibly due to deep surface cracks, which were visible on some specimens of brand 16 .

\section{(b) Variations in Specimens and Changes From Preheating}

Table 2 gives the maximum, minimum, and average values of modulus of elasticity and the coefficient of variation ${ }^{5}$ obtained for specimens following the preheating. The large ranges of the average values for the different brands and the range in values for specimens of each brand indicated the necessity of adjusting the stresses for the creep tests.

TABLE 2.-Tensile moduli of elasticity of firebrick at room temperature after preheating at $900^{\circ} \mathrm{C}$ for one-half hour, and percentage change caused by preheating

\begin{tabular}{|c|c|c|c|c|c|c|c|c|}
\hline \multirow{3}{*}{ Brand No. } & \multicolumn{5}{|c|}{ Modulus of elasticity after preheating } & \multicolumn{3}{|c|}{$\begin{array}{l}\text { Change caused by } \\
\text { preheating } a\end{array}$} \\
\hline & \multirow{2}{*}{$\begin{array}{l}\text { Num- } \\
\text { ber of } \\
\text { speci- } \\
\text { mens } \\
\text { tested }\end{array}$} & \multirow{2}{*}{$\begin{array}{l}\text { Max- } \\
\text { mum }\end{array}$} & \multirow{2}{*}{$\begin{array}{l}\text { Mini- } \\
\text { mum }\end{array}$} & \multirow{2}{*}{$\begin{array}{l}\text { Aver- } \\
\text { age }\end{array}$} & \multirow{2}{*}{$\begin{array}{l}\text { Coeffi- } \\
\text { cient of } \\
\text { varia- } \\
\text { tion }\end{array}$} & \multirow{2}{*}{$\begin{array}{l}\text { Num- } \\
\text { ber of } \\
\text { speci- } \\
\text { mens }\end{array}$} & \multicolumn{2}{|c|}{$\begin{array}{l}\text { Decrease in } \\
\text { modulus }\end{array}$} \\
\hline & & & & & & & $\begin{array}{l}\text { Aver- } \\
\text { age }\end{array}$ & $\begin{array}{l}\text { Stand- } \\
\text { ard de- } \\
\text { viation }\end{array}$ \\
\hline & & $\begin{array}{c}1,000 \\
l b / \text { in }^{2}\end{array}$ & $\begin{array}{c}1,000 \\
l b / \text { in }^{2}\end{array}$ & $\begin{array}{l}1,000 \\
\text { lb/in.2 }\end{array}$ & Percent & & Percent & Percent \\
\hline 19 & 14 & 5,280 & 3,690 & 4,280 & 10.9 & 10 & 2.3 & 2.0 \\
\hline $18 \ldots$ & 2 & 2,750 & 2,700 & 2,725 & 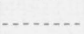 & 0 & $\ldots$ & ... \\
\hline $1 \ldots$ & 16 & 2,340 & 1,130 & 1,915 & 17.5 & 8 & 1.1 & 2.3 \\
\hline $6 \ldots$ & 4 & 1,740 & 1,650 & 1,695 & 2.5 & 2 & 4.1 & ... \\
\hline $11 \ldots$ & 12 & 1,450 & 320 & 615 & 64.3 & 4 & 2.7 & 2.1 \\
\hline $7 \ldots$ & 10 & 1,610 & 705 & 1,185 & 28.6 & 6 & 3.5 & 1.8 \\
\hline $15 \ldots$ & 10 & 1,965 & 1,390 & 1,725 & 12.8 & 4 & 13.8 & 1.4 \\
\hline $16 \ldots$ & 27 & 415 & 175 & 275 & 20.5 & 13 & 31.8 & 9.0 \\
\hline $17 \ldots$ & 24 & 615 & 310 & 435 & 21.3 & 14 & 19. 7 & 4. 6 \\
\hline
\end{tabular}

a The modulus of elasticity was not determined on all specimens before preheating. Therefore, the percentage decrease is given only for those specimens for which the modulus had been determined both before and after preheating.

When the tensile moduli of elasticity were obtained both before and after the preheating, the change (expressed in percentage of the original value) was always a reduction, and the average values for each brand are given in table 2. Similar changes were observed by Heindl and Pendergast [7]. These changes probably indicated partial fracture of the specimens, resulting in decreased effective cross sections. The highsilica bricks (brands 15, 16, and 17) had the largest changes, and the remaining brands of brick had comparatively small changes.

(c) Comparison of Elasticity in Tension and in Compression

At room temperature the modulus in compression was greater than the modulus in tension, as measured on two specimens from each of eight brands. These differences ranged from 3 to 18 percent and averaged 8 percent.

\footnotetext{
${ }^{5}$ Manual for interpretation of refractory test data, ASTM Standards on Refractory Materials (Feb. 1935).
} 


\section{(d) Changes With Age of Specimens}

The tensile modulus of elasticity of prepared specimens changed slightly as the result of storage for periods up to 5 years at room temperature. The moduli of elasticity of specimens for brand 17 decreased an average of 0.8 percent during an average storage time of 308 days, possibly because of localized expansion and pitting resulting from hydration of uncombined lime. The moduli of specimens of brands 15 and 16 increased approximately 5 percent as the result of storage for about 2 years, whereas those of specimens of the remaining brands increased from 1.3 to 3.4 percent for similar aging periods. There was no definite relation between storage time and amount of change.

\section{(e) Changes Resulting From Creep Tests}

The changes in modulus of elasticity in tension at room temperature resulting from creep tests were plotted for single specimens from creep tests in compression in figure $2, \mathrm{~B}$ and for single specimens from creep tests in tension in figure $3, \mathrm{~B}$.

These changes in moduli of elasticity indicated a characteristic behavior for brick of each brand. The changes in moduli of elasticity resulting from creep tests at all test temperatures for specimens of brands 15 and 18 were small, although their compositions were widely different. The decrease in moduli of elasticity for specimens of brand 16 used in creep tests at all test temperatures, except the test at $950^{\circ} \mathrm{C}$ in compression, were large. The decrease in moduli of specimens of brand 17 used in creep tests at temperatures ranging from $125^{\circ}$ to $700^{\circ} \mathrm{C}$ also were large, although the moduli of specimens used in the range from $800^{\circ}$ to $950^{\circ} \mathrm{C}$ increased. After creep tests at temperatures of $125^{\circ}$ to $850^{\circ} \mathrm{C}$, moderate alterations of moduli of elasticity were observed for specimens of fire-clay brick; of these the specimens for brands 6,7 , and 11 from the compressive creep tests at $900^{\circ}$ and $950^{\circ} \mathrm{C}$ had notable increases in moduli. Alterations in moduli were not determined for specimens of brand 1 from creep tests at $900^{\circ}$ and $950^{\circ} \mathrm{C}$, nor for the specimen of brand 7 from the tensile creep tests at $950^{\circ} \mathrm{C}$, due to breaking or warping of the specimens during the tests. However, a specimen of brand 1 tested in tension at $950^{\circ} \mathrm{C}$ with a stress factor of only $1 \times 10^{-5}$ had a small increase in modulus of elasticity. The high-alumina brick, brand 19 , had its greatest reduction in modulus cf elasticity at $800^{\circ} \mathrm{C}$ during both tensile and compressive creep tests, but moderate changes occurred during tests at other temperatures.

The changes in modulus of elasticity, plotted in figures $2, \mathrm{~B}$ and $3, \mathrm{~B}$, resulted from the combination of the time, temperature, and stress con-

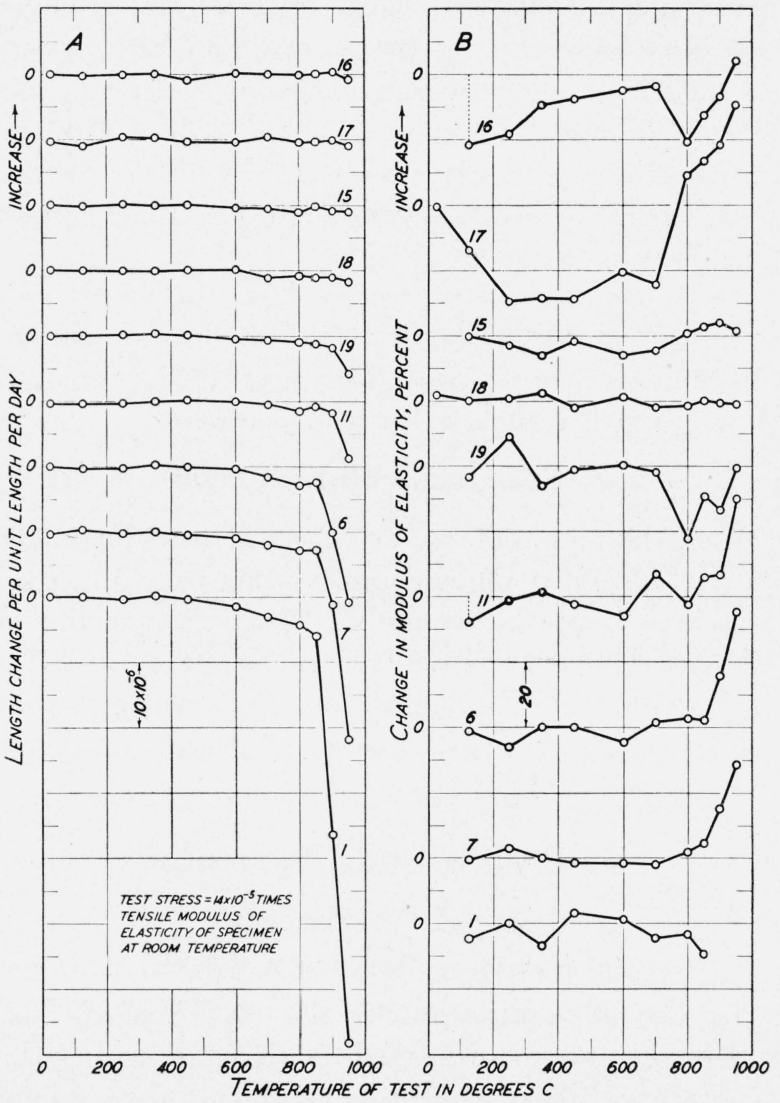

Figure 2.-Changes effected by creep terts in compression.

The numbers accompanying the curves designate the brand numbers. $A$ shows the average length chenge occurring per day, during approximately 240 days, while the specimens were loaded and at the test temperature indicated. $B$ shows the percentage change in tensile moduli of elasticity, determined at room temperature before and after the creep test, resulting from a creep test at the indicated temperature. Moduli of elasticity of specimens of brand 1 were not obtained following tests at $900^{\circ}$ and $950^{\circ} \mathrm{C}$ because the specimens were deformed during the creep tests.

ditions of each creep test. These conditions should change the moduli only so far as they affect the physical texture (crystal and glass phases) of the specimens. For a creep test at a particular temperature, whether in tension or compression, the temperature and time factors are constant, and, therefore, the stress is the only variable. Subtracting the change in modulus that occurred during a test in tension from the change in modulus 
that occurred during a corresponding test in compression may supply an indication of the extent to which the direction of stress either supplemented or hindered the volume changes resulting from textural changes. As data on textural changes are not available, the only observation possible at this time is that the changes in moduli during compression were not consistently greater or less than those during tension. This applies
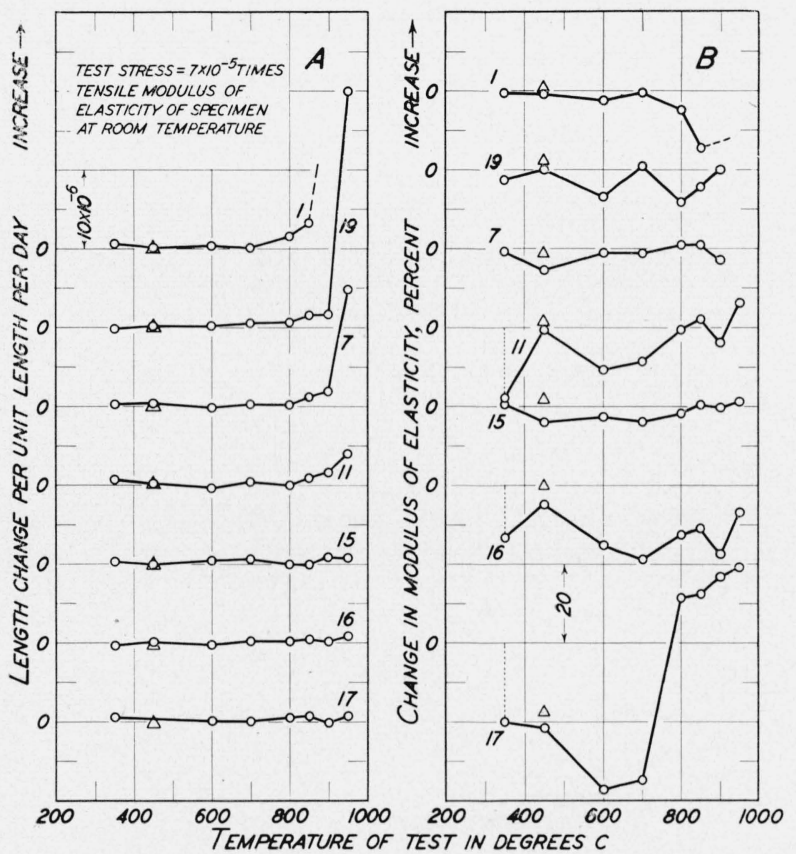

FiguRE 3.-Changes effected by creep tests in tension.

The numbers accompanying the curves designate the brand numbers. Data, indicated by triangles, were obtained from duplicate tests. $A$ shows the average length change occurring per day, during approximately 240 days, while the specimens were loaded at the test temperature indicated. $B$ shows the percentage change in tensile modulus of elasticity, determined at room temperature before and after the creep test, resulting from a creep test at the indicated temperature. The changes in moduli were not obtained for specimens that broke during creep tests, and for these specimens the creep values are for time intervals as follows: Brand 1 at $900^{\circ} \mathrm{C}$ broke after 4 days and no creep values were obtained; brand 1 at $950^{\circ} \mathrm{C}$ broke after 6 days, and the ereep per day during the first 3 days was $923 \times 10^{-6}$; hrand 19 at $950^{\circ} \mathrm{C}$ broke aiter 35 days, and the creep rate shown applies to the first 5 days; brand 7 at $950^{\circ} \mathrm{C}$ broke after 123 days, and the creep rate shown applies to the first 95 days.

either for specimens of one composition at the several test temperatures or for the several compositions at one temperature.

As the sense of the sustained stress in the creep tests did not have a consistent effect on the changes of the moduli of elasticity, these changes were apparently the result of the heat treatment. The lack of similarity of the changes from the preheating at $900^{\circ} \mathrm{C}$ (unstressed and heated one-half hour, see table 2) and the changes following the creep tests at $900^{\circ} \mathrm{C}$ (stressed for 240 days, see figs. 2,B and $3, \mathrm{~B}$ ) indicated that the duration of the exposure at the high temperature was an important factor. Preheating decreased the average moduli of the specimens representing all brands, whereas the combined effects of the stress and the longer exposure at $900^{\circ} \mathrm{C}$ in the creep tests increased the moduli of brand 17 , both when subjected to tensile stress and to compressive stress, and of brands $6,7,11$, and 15 when subjected to compressive stress.

\section{Length Changes}

\section{(a) Length Changes and Time}

Graphs of length changes and time for the duration of a creep test are plotted in figure 4. The graphs for the specimens of brands 7 and 17 tested at $900^{\circ} \mathrm{C}$ only are given. Results from compressive tests are shown at $A$ and $C$ and from tensile tests at $B$ and $D$. Corresponding graphs for all of the specimens tested were similar.

The thermal-expansion values of several specimens of a given brand were seldom in agreement. These differences, for example, ranged from 0.02 to 0.065 percent at $950^{\circ} \mathrm{C}$ for specimens of those brands having a total thermal expansion of approximately 0.6 percent between $25^{\circ}$ and $950^{\circ} \mathrm{C}$. Also, irregular curves were obtained when the total thermal-expansion values from the several creep tests were plotted against the test temperatures. This was true whether the data were obtained with one specimen, or with more than one specimen.

The thermal-expansion and thermal-contraction values for any one specimen were rarely equal, and for all specimens the contraction ranged from 0.075 percent greater to 0.085 percent less than the expansion.

Deformations observed during the 15 minutes following the application or removal of the load were considered as primarily elastic. As the creep tests probably altered the specimens, the elastic deformations resulting from loading and from unloading were not necessarily equal.

Figure 4 shows marked differences in the creep $(m)$, or change in length during the time loads were applied, for brands 7 and 17. The curve for the specimen of brand 7 in compression illustrated the type of curves $[8,9,10]$ associated with brands 
of brick having comparatively large creep rates during loading at constant temperature. For bricks of this type the rate of creep is large during the first 20 to 40 days and considerably smaller and practically constant for the remainder of the 240 days. Graphs showing little total creep, only a few times the precision of measurement, were obtained for specimens of most of the brands of brick, as illustrated by results for brand 17.
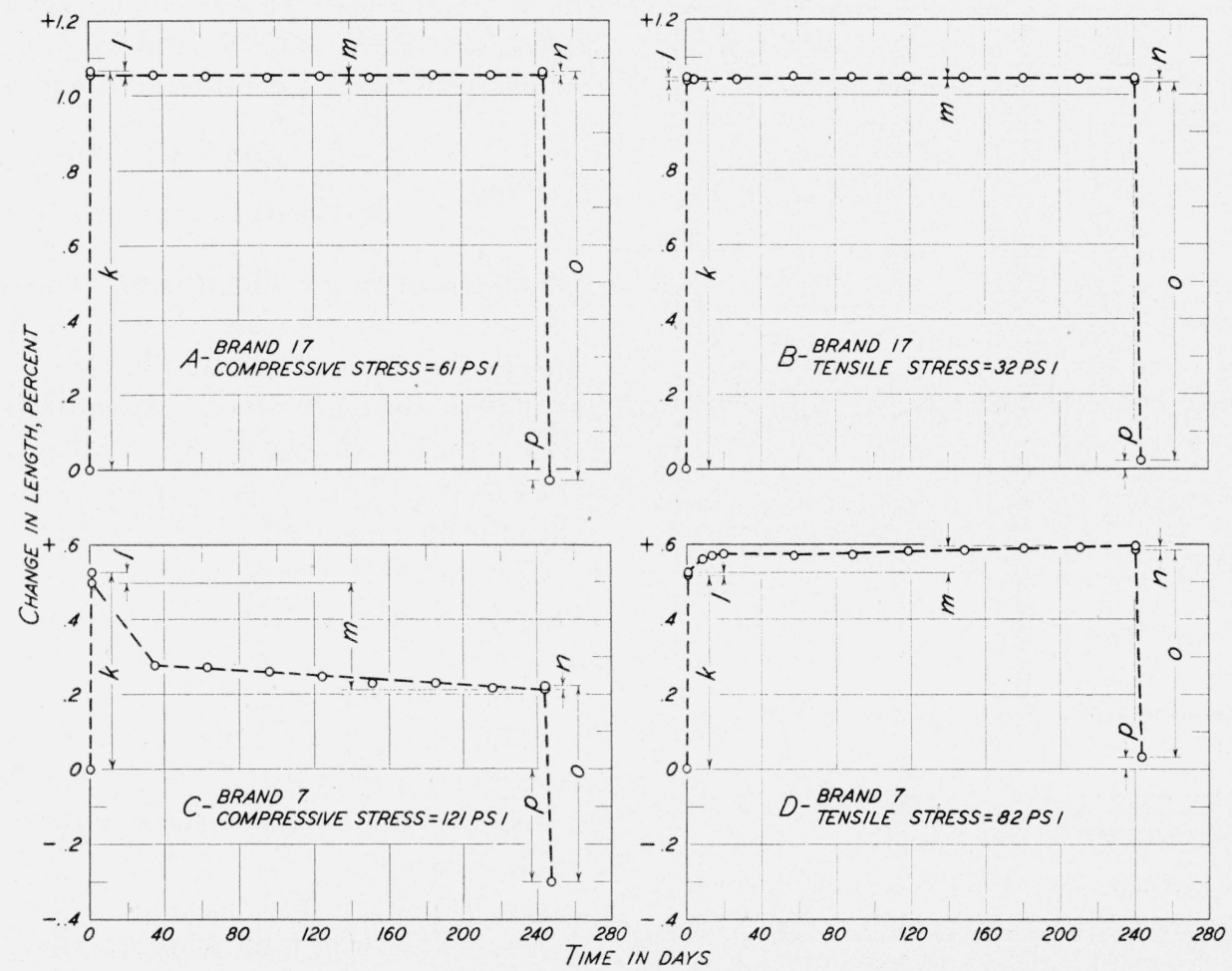

FIGURE 4.-Length changes occurring during the course of compressive and tensile creep tests at $900^{\circ} \mathrm{C}$ for two brands of firebrick.

$k$, Thermal expansion resulting from heating from room temperature to the test temperature; $l$, the elastic deformation at $900^{\circ} \mathrm{C}$ due to loading; $m$, total creep occurring during stressing and heating at $900^{\circ} \mathrm{C} ; n$, elastic deformation due to removal of load; $o$, thermal contraction resulting from cooling from the test temperature to room temperature; and $p$, overall length change.

Values of total creep and over-all length change, for the same specimen and test temperature, were rarely equal. The over-all change included not only creep but also differences between thermal expansion and contraction and between elastic deformations caused by loading and unloading.

The durations of the various creep tests were about 240 days, as shown in figure 4 , but were not identical, and therefore the creep per day was calculated (total creep divided by loading time in days), and the results are plotted in figures $2, \mathrm{~A}$ and $3, A$. curves represents data from a single specimen. Data from tests in tension at room temperature, at $125^{\circ}$ and $250^{\circ} \mathrm{C}$ are not reported. The following discussion applies to both figures $2, \mathrm{~A}$ and $3, \mathrm{~A}$.

Indicated changes in length, which averaged less than 0.00016 percent per day, probably result from internal changes in the specimen because, for a given temperature, they may be either increases or decreases regardless of the direction of the applied stress. The presence of these changes, when larger than the precision of measurement, obscured a determination of the minimum temper- 
ature at which the length changes may be assigned definitely to creep caused by the applied stress [11]. However, it is obvious that the curves in figure 2,A for specimens of brands 1 and 7 indicate some creep at test temperatures as low as $600^{\circ} \mathrm{C}$, whereas for specimens of brands 16 and 17 , creep was not definite below $950^{\circ} \mathrm{C}$.

Specimens of brand 1 had the greatest rate of creep under compressive stress at $950^{\circ} \mathrm{C}$ and ruptured while under tensile stress. An examination of the properties of this brand (table 1) indicates it to be unique in that it contained over 1 percent of $\mathrm{P}_{2} \mathrm{O}_{5}$ and had the lowest porosity. Its pyrometric cone equivalent (pce) was 34 , yet specimens for brand 1 had 85 times as much creep asspecimens for brand 16, which had a pce of 29-30. Specimens for fire-clay bricks, brands $1,6,7$, and 11 , all had large creep values at $950^{\circ} \mathrm{C}$. Specimens for bricks containing the higher percentages of silica (brands 15, 16, and 17) had small creep values. Specimens for the 55-percent-alumina brick, brand 18, also had small creep values, probably because the predominant phase was mullite. However, specimens for the 80-percentalumina brick, brand 19 , in which the predominant phase was corundum, had moderate creep values at $950^{\circ} \mathrm{C}$. Brick of both brands contained an intermediate amount of glassy bond.

\section{(c) Creep and Direction of Stress}

Compressive stresses, although twice the tensile stresses, caused approximately the same creep as the tensile stresses for specimens for brands 15 , 16 , and 17 at $950^{\circ} \mathrm{C}$. At the same temperature, specirnens for brands 7 and 11 had creep values for compressive tests about twice the values for tensile tests, even though the specimen of brand 7 broke in the tensile test after 123 days of loading. The tensile specimen of brand 19 had a creep value about five times larger than the compressive specimen in the tests at $950^{\circ} \mathrm{C}$. Specimens of brand 1 had an extreme difference in tensile and compressive creep, the tensile value (before the specimen broke) being approximately 13 times the compressive value at $950^{\circ} \mathrm{C}$. This weakness in tension of specimens of both brands 1 and 19 at $950^{\circ} \mathrm{C}$ was indicated by breakage during the tensile creep tests (see legend to fig. 3).

(d) Creep at $950^{\circ} \mathrm{C}$ and Tensile-Stress Factor

Rates of creep in tension at $950^{\circ} \mathrm{C}$, obtained from tests with single specimens, are plotted in figure 5 with respect to stress factor. The curves indicate an enormous difference in the reaction of the specimens of different brands to different stresses.

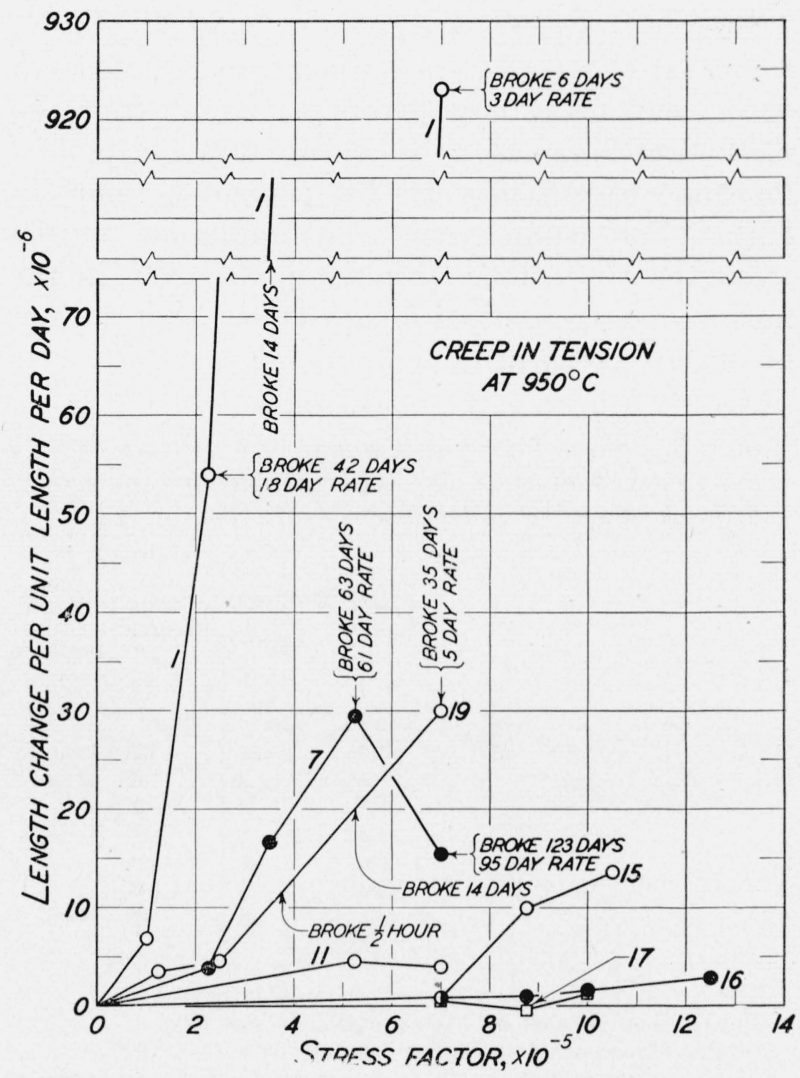

Figure 5.-Creep at $950^{\circ} \mathrm{C}$ with respect to tensile-stress factor.

The stress for each creep specimen is the product of the stress factor and its tensile modulus of elasticity. The numbers accompanying the curves designate the brand numbers. The number of days of loading included in the daily rate from the beginning of the test is noted for some of the specimens that broke. Creep rates were not determined for the specimen of brand 1 that broke after 14 days, and specimens of brand 19 that broke after one-half hour and after 14 days. Two specimens, not indicated, of brand 17 tested with stress factors equal to $17.5 \times 10^{-5}$ and $25 \times 10^{-5}$ broke within one-half minute.

Variations between specimens of brand 19 were shown by decreases in time before breakage as the stress factor was reduced from $7 \times 10^{-5}$ to $3.75 \times$ $10^{-5}$. Also, variation in specimens of brand 7 was shown by a greater creep rate for a stress factor equal to $5.25 \times 10^{-5}$ than for a factor equal to $7 \times 10^{-5}$.

\section{(e) Comparative Stresses for Equal Creep Rates at $950^{\circ} \mathrm{C}$}

For the purpose of evaluating the brands of brick, "comparative stresses" causing equal creep rates in tension at $950^{\circ} \mathrm{C}$ were calculated. The 
comparative stress is the product of the stress factor causing a creep rate of $1 \times 10^{-6}$ per day (obtained from the curves in fig. 5), and the average modulus of elasticity. The stress factors and comparative stresses are given in table 3 . As the comparative stresses are derived from results from one specimen and large errors may result from the method of calculation, the values given in table 3 for some brands may be 300 percent or more in error. For comparison, the minimum tensile strengths of specimens broken in the tests, or the maximum stresses used for specimens that did not break, are given in table 3 , column 4 .

TABLE 3.- Stress factors and comparative stresses causing creep rates equal to $1 \times 10^{-6}$ (in./in.)/ day, and trengths of firebrick at $950^{\circ} \mathrm{C}$ in tension

\begin{tabular}{|c|c|c|c|c|}
\hline Brand & $\begin{array}{l}\text { Stress } 1 \\
\text { factor }\end{array}$ & $\begin{array}{c}\text { Compara- } \\
\text { tive } 2 \\
\text { stress }\end{array}$ & $\begin{array}{l}\text { Tensile } \\
\text { strength }\end{array}$ & $\begin{array}{c}\text { Time } \\
\text { loaded } \\
\text { before } \\
\text { breaking }\end{array}$ \\
\hline & $\times 10^{-5}$ & $p s i$ & $p s i$ & \\
\hline $19 \ldots$ & 0.35 & 15 & ${ }^{3} 175$ & $1 / 2 \mathrm{hr}$. \\
\hline $1 \ldots \ldots$ & .15 & 3 & ${ }^{3} 32$ & 42 days. \\
\hline $11 \ldots \ldots$ & 1.1 & 7 & ${ }^{4} 30$ & \\
\hline $7 \ldots$ & 0.55 & 6 & ${ }^{3} 65$ & 63 days. \\
\hline 15 & 7.0 & 120 & ${ }^{4} 205$ & \\
\hline $16 \ldots$ & 8.5 & 23 & 445 & \\
\hline 17 & 9.6 & 42 & ${ }^{3} 65$ & 1트 $\mathrm{min}$. \\
\hline
\end{tabular}

: Taken from curves in figure 5 for a creep rate of $1 \times 10^{-6}$.

2 Product of stress factor and average modulus of elasticity

${ }^{3}$ Minimum specimen stress causing breakage at $950^{\circ} \mathrm{C}$.

${ }^{4}$ Maximum specimen stress used in tests at $950^{\circ} \mathrm{C}$; specimen not broken after 240 days.

These comparative stresses indicated great differences in the load-bearing capacities of the specimens of different brands. Specimens of brand 15 were superior because they had the highest comparative stress, resulting from a low creep rate at a relatively high stress, and also because they had the highest tensile strength. Specimens of brands 16 and 17, having high silica content, had moderate comparative stresses because of low strength, even through their resistance to creep at a relatively low stress was high. However, for specimens of these brands the comparative stresses are such a large fraction of the tensile strengths as to leave little provision for temporary overloads. Specimens of the fire-clay bricks, brands 1, 7, and 11, had comparatively small comparative stresses and their strengths fell in the same range with the strengths of the specimens of the high-silica brick. Specimens of the high-alumina brick, brand 19 , had an intermediate comparative stress resulting from their large creep rate, but they had a large reserve in strength.

\section{(f) Growths and Shrinkages Other Than Creep}

If the creep were the only permanent change occurring during a creep-test cycle, then $p$ would be equal to $m$ (fig. 4). However, thermal expansion $(k)$ and contraction $(o)$, and elastic deformation following loading $(l)$ and elastic deformation following unloading $(n)$, were not equal. The difference between $m$ and $p$ is a measure of these combined inequalities. This difference may result in either growth or shrinkage.

The growths were largest for specimens of silica brick, brand 17 [12]. As creep was negligible for this brick, any over-all change in the length between the gage marks was attributed to growth or shrinkage. These over-all changes, plotted in figure $6, \mathrm{~A}$, were appreciable even for the test at $125^{\circ} \mathrm{C}$, in compression, and greatest for the tensile test at $700^{\circ} \mathrm{C}$. Growths for these particular specimens were considerably greater than growths for compressive tests at all temperatures except $450^{\circ} \mathrm{C}$.

The characteristic texture and mineral composition of silica brick [13] may account for these comparatively large over-all changes, which are associated with decreases in modulus of elasticity for tests at and below $700^{\circ}$ C. Sintering and decomposition of partially rehydrated, uncombined lime may be factors in the limited over-all changes and increases in modulus of elasticity for tests at and above $800^{\circ} \mathrm{C}$.

To determine the extent of the growth of unstressed specimens during repeated heat treatments, five 1-inch-square specimens from one brick of brand 17 were included in the creep furnaces for the tests indicated in figures $6, \mathrm{~B}$ and C. Excepting the pronounced effect of the first heat treatments (specimens 2 and 5, fig. 6,B, and 4 , fig. $6, \mathrm{C}$, at $350^{\circ} \mathrm{C}$; and specimens 1 , fig. $6, \mathrm{~B}$, and 3 , fig. $6, \mathrm{C}$, at $600^{\circ} \mathrm{C}$ ), the curves have sufficient similarity to indicate that they are real and reproducible. The cumulative growths resulting from the series of heat treatments for these five specimens range from 0.231 to 0.268 percent.

Creep specimens of the remaining brands had much smaller growths, or shrinkages, than were found for brand 17. Specimens of the high- 
alumina brick, brand 19 , had growth resulting from the creep tests at $700^{\circ} \mathrm{C}$ only. The fire-clay bricks had little tendency to grow or shrink. For brands 15 and 16 the over-all length-change curves were somewhat similar to those for brand 17 , but the changes were less than half as large.

\section{Summary of Results}

The changes in moduli of elasticity in tension of preheated specimens as the result of storage at room temperature for periods as long as 5 years were small. These changes fell in the range from about 1-percent decrease in moduli to 5-percent increase. The changes were not proportional to time. siliceous bricks containing 81 or 96 percent of silica as the result of either tensile or compressive creep tests at and below $700^{\circ} \mathrm{C}$. For brick containing 96 percent of silica and a majority of the fire-clay bricks, increases in tensile moduli at room temperature resulted from compressive creep tests at and above $800^{\circ} \mathrm{C}$.

Small changes in length were found at test temperatures of $450^{\circ} \mathrm{C}$ and lower, but the changes did not depend on the direction of the stress and were attributed to internal adjustments of the specimens. Deformations were small also at all test temperatures for specimens of two brands of siliceous, one silica, and one high-alumina brick. Large deformations were obtained at test tem-
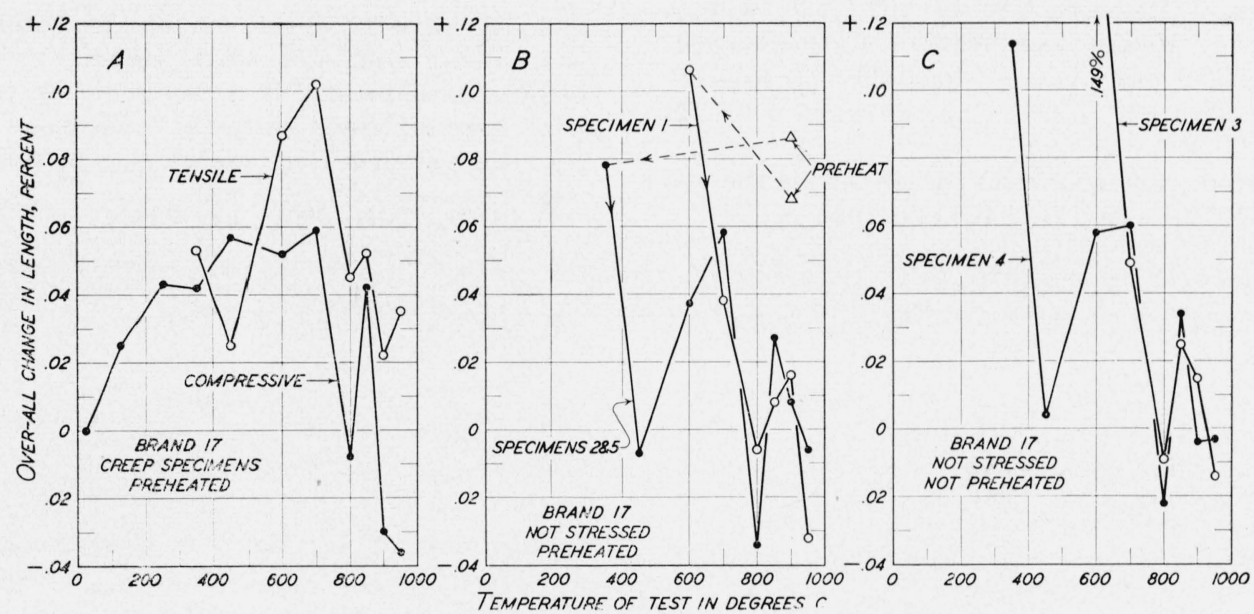

FIGURE 6.-Over-all, or net, length change of silica brick observed after heating from room temperature to indicated test temperature, maintaining test temperature approximately 240 days and cooling to room temperature.

Solid circles show values for sfecimens treated in the furnace for compressive tests; open circles show values for specimens treated in the furnace for tension tests. All values in figures $A, B$ and $C$ for a given temperature and furnace apply to specimens tested simultaneously. A, Over-all length changes for preheated specimens used in creep tests. Each point is for a new specimen; $B$, over-all length changes for three unstressed specimens heated at progressively higher tem reratures after having keen preheated at $c 00^{\circ} \mathrm{C}$ for one-half hour. The triangles indicate the length changes resulting from this preheating; $C$, over-all length chang es for two unstressed specimens heated at progressively higher temperatures. The specim ens had not been preheated.

The average tensile moduli of elasticity at room temperature of the different brands ranged from 275,000 to $4,280,000$ psi, with coefficients of variation ranging from 2.5 to 64.3 percent. Indications of variations within individual specimens were noted.

At room temperature the compressive moduli of elasticity of preheated but not creep-tested specimens averaged 8 percent greater than the tensile moduli.

At room temperature significant reductions occurred in the tensile moduli of elasticity of peratures from $850^{\circ}$ to $950^{\circ} \mathrm{C}$ for fire-clay bricks and a high-alumina brick containing 80 percent of alumina.

Creep values for specimens tested in compression were not proportional to creep values for specimens tested in tension.

The stress that would produce a $1 \times 10^{-6}$ (in./in.)/ day tensile creep at $950^{\circ} \mathrm{C}$ ranged from 3 psi for a fire-clay brick containing 48 percent of $\mathrm{SiO}_{2}$ to 120 psi for one containing 65 percent of $\mathrm{SiO}_{2}$.

Unstressed specimens of silica brick showed 
growths as large as 0.27 percent resulting from repeated heatings at several temperatures without load.

\section{References}

[1] A. C. Elliot and R. J. Montgomery, A new type of thermal shock, J. Can. Ceram. Soc. 6, 44 (1937).

[2] Shin-ichi Suzuki, Modulus of elasticity and spalling. I, J. Japan. Ceram. Assn. 47, 230 (1939).

[3] J. H. Partridge and C. F. Adams, Creep of refractory materials at high temperatures and its bearing on the performance of glasshouse pots, J. Soc. Glass Tech. 23, 141 (1939).

[4] R. A. Heindl and L. E. Mong, Young's modulus of elasticity, strength and extensibility of refractories in tension, J. Research NBS 17, 463 (1936) RP923.

[5] Raymond A. Heindl and William L. Pendergast, Deformation and Young's modulus of fire-clay brick in flexure at $1,220^{\circ} \mathrm{C}, \mathrm{J}$. Research NBS 19, 353 (1937) RP1030.

[6] F. H. Norton, New apparatus for measuring the viscosity of glass, Glass Ind. 16, 143 (1935).
[7] Raymond A. Heindl and William L. Pendergast, Young's modulus of elasticity at several temperatures for some refractories of varying silica content, J. Research NBS 13, 851 (1934) RP747.

[8] F. H. Norton, Flow of ceramic bodies at elevated temperatures, J. Am. Ceram. Soc. 19, 129 (1936).

[9] F. H. Norton, Critical examination of load test of refractories, J. Am. Ceram. Soc. 22, 334 (1939).

[10] F. H. Clewes, H. M. Richardson, and A. T. Green, The behavior of refractory materials under stress at high temperatures, parts I and II, Trans. Brit. Ceram. Soc. 43, 223 (1944). Ceram. Abs. 23, 89 (1944).

[11] G. A. Kirkendale and R. J. Montgomery, A proposed gloss firing cycle based upon the temperature of plastic flow of the body, J. Can. Ceram. Soc. 3, 25 (1934).

[12] G. R. Rigby, A. E. Dodd, R. P. White, and A. T. Green, Investigation of the permanent expansion of silica products containing cristobalite, Trans. Brit. Ceram. Soc. 42, 11 (1943).

[13] W. A. Semple and R. J. Montgomery, Spalling resistance of fused silica vs. quartz and calcined fireclay grog, J. Can. Ceram. Soc. 9, 40 (1940).

Washington, June 13, 1946. 